\title{
The relative effectiveness of an inanimate stimulus and a live surrogate during imprinting in Japanese quail, Coturnix coturnix japonica
}

\author{
PAUL W. BEAVER, PATRICK E. SHROUT, and ECKHARD H. HESS \\ University of Chicago, Chicago, Illinois 60637
}

\begin{abstract}
It has been demonstrated repeatedly that stimuli vary in their effectiveness in eliciting and maintaining imprinting. Agreement has not been reached, however, with regard to the ideal imprinting model for laboratory studies. This situation is in part a result of the inability to repiicate precisely natural parameters in the laboratory. Thus laboratory results are often inconsistent with field research. In order to develop a more biologically appropriate imprinting stimulus, a live Japanese quail hen was conditioned to serve as an imprinting object. An imprinting study was then performed to assess the dimensions of effectiveness of the live model. Comparisons between the live model and a decoy yielded different patterns of imprinting in young Japanese quail.
\end{abstract}

One of the first investigators to treat imprinting within a comprehensive theoretical framework was Konrad Lorenz (1971), who, in 1935, originally proposed that imprinting consisted of an instinctive behavior pattern which lacked an innately determined object. In other words, while the process of attachment is innate, there is no innate recognition of the conspecific parent.

Recent theoretical papers on imprinting have reemphasized Lorenz's second point, that there exists no innate recognition of the conspecific parent. Rajecki (1973) questioned the "ethological approach" to imprinting by noting that following could be promoted by a wide range of visual stimuli, including footballs, floating cubes, light flicker, and rotating disks. Similarly, Hoffman and Ratner (1973) concluded that the eliciting stimuli in imprinting are "quite nonspecific in that any of a wide variety of moving stimuli can elicit it" (p. 532).

Even though no one stimulus dimension has been found to be paramount in eliciting imprinting, many stimulus dimensions of objects serving as surrogates in an imprinting experiment have been shown to vary in their effectiveness in eliciting approach and following in young precocial birds. Moving objects were found to be superior to motionless objects (Moltz, Rosenblum, \& Stettner, 1960; Weidmann,

This research was supported by Grant 776 of the National Institute of Mental Health, awarded to E. H. Hess. The authors express gratıtude to Slobodan Petrovich and Elizabeth Goodwin for their many helpful comments on an earlier draft of this paper Requests for reprints should be sent to E. H. Hess, Department of Behavioral Sciences, University of Chicago, Chicago, Illınois 60637. The first two authors are listed alphabetically.
1956), and articulated movement has been shown to be especially effective (Fabricius, 1951). Various objects utilized as imprinting stimuli should be within a particular size range (Smith, 1962); in domestic chicks, the optimal size for eliciting following was demonstrated to be $10 \mathrm{~cm}$ (Schulman, Hale, \& Graves, 1970). Three-dimensional objects produced better imprinting than did identical objects presented in two-dimensional form via motion picture film (Klopfer, 1971). Despite early contentions that the color of the imprinting stimulus is unimportant (Jaynes, 1958), innate color preferences in imprinting stimuli have been repeatedly demonstrated (Goodwin \& Hess, 1969; Gray, 1961; Kovach, 1971; Schaefer \& Hess, 1959; Smith \& Bird, 1964). The relevance of the shape of the stimulus has been shown to be important for imprinting (Hess, 1959; Hess \& Hess, 1969; Huber, 1967; Ramsay \& Hess, 1954; Waller \& Waller, 1963). For example, Hess and Hess (1969) have demonstrated that, for ducklings, a duck decoy was superior to a human in eliciting approach, even though it lacked articulated motion and feedback interaction. In addition, auditory stimuli have been showri to play an important, perhaps even predominant, role in imprinting of many species (Klopfer \& Gottlieb, 1962). Gottlieb (1971) has further demonstrated that young nidifugous birds may even possess a very high degree of species specificity in their auditory preferences.

Despite all of this research on the parameters of imprinting stimulus effectiveness, little agreement has been reached in the many laboratories as to the nature of the stimulus which should be ideally employed in laboratory investigations of imprinting. Typical imprinting stimuli which are currently used 
in laboratory investigations would include: flickering lights, colored spheres, and toy trains. This variance in the use of imprinting stimuli in laboratory investigation may be a contributing factor to the apparent inconsistencies in the imprinting literature. In addition, since these laboratory stimuli are often somewhat discrepant from the stimuli characteristics of the natural parent, comparisons between natural observations and laboratory observations of imprinting tend to be limited. Indeed, considering the nature of imprinting stimuli employed, it is not surprising that research in the laboratory has not always substantiated findings in the field. In light of this situation, it was our desirc to devise a more natural imprinting stimulus which could be successfully adapted for use in laboratory investigation.

\section{METHOD}

\section{Tr raining of the Live Imprinting Stimulus}

An adult, nonbroody, nonvocalizing Japanese qual hen (Coturnix coturnix japonica) served as the live imprinting stımulus Shapıro and Agnew (1975), Shapıro (Note 1), and Storey and Shapıro (Note 2) have previously used live models in the laboratory investıgation of imprintıng. The control over the behavior of the live models in their studies, however, was a.chieved by the use of physical restraints, a method which evoked aggressive behavior on the part of the model. In our study, experimental control over the behavior of the live model was achieved through operant techniques; this method resulted in a naturally locomotıng imprintıng stımulus.

A Hess imprinting apparatus was modified to contain the live adult by enclosing the runway with a fine wire mesh. Allowing her to habituate to this environment, the quail hen was left in the apparatus several days before the tranning procedure was initiated. The hen was then water deprived for periods up to $48 \mathrm{~h}$. dllowing experimental control to be established and maintained over the anımal The operant response required of the animal uas simply to approach and peck at a 50 - $\mathrm{ml}$ water bottle; this bottle was moved around the circular track at a speed regulated by remote control, forcing the quall to constantly locomote in order to be reinforced The bottle Itself was suspended $5 \mathrm{~m}$. above the runway (about eye level to the uird), and the water flow was adjusted such that the burd was not immediately sated withın the experimental session. A speed which elicited a smooth locomotory performance from the hen was $1.5 \mathrm{in} . / \mathrm{sec}$. It should be noted that this procedure was especially developed for Japanese quail, a species which seems to adapt well to experımental manipulations.

The central light source of the apparatus was used to signal the intiation and termination of the imprinting trials The sequence used was "light on" for the intiation and "light off" for the termination of each trial. Undesirable behavior on the part of the live model was eliminated during the training trials by switching the light off and retracting the water bottle immediately upon the occurrence of such behavior.

Several undesirable behaviors on the part of the live model were confronted in the course of the training and experimental sessions. One of these behaviors was a propensity by the hen to aggressively peck at the chick that was to follow her. Not only was this behavior negatively reinforced by the technique noted above, but also ethological considerations were taken into account to reduce the behavior. The experimental room was put on a lighting schedule which replicated the spring mating season light cycle, and the live model was allowed to frequently socialize with other quail, particularly males. These combined approaches essentially eliminated the aggressive tindencies of the hen An additional undesirable behavior which had 10 be controlled, was a tendency of the hen to run past the water bottle and wat for it to come to her This behavior was eliminated by simply stopping the water bottle each time the hen engaged in the behavior

\section{Subjects}

The subjects were 70 Japanese quail, hatched in a Brower Humidarre, Model 150, forced-air incubator. Laboratory imprinting has been reported in the species (Ozman, 1970, 1973). The birds were maintained in visual and social isolation until the tume they were used for imprinting. Each bird was kept in a green cardboard box, measurnng $4 \times 6 \times 4 \mathrm{n}$. The boxes were stored, at a temperature of approximately $99^{\circ}$, in a Favorite Incubator, manufactured by Leahy Manufacturing Co.

\section{Procedure}

The quail subject's were subjected to one of the imprinting models at the following range of posthatch age intervals (in hours): 5 to 9,10 to 14,15 to 19,20 to 29,30 to 39 , 40 to 59 , and 60 to 79 . Five birds individually were tested at each age interval under one of the two stimulus conditions. The experimental condition consisted of the use of the live model, while the control condition employed a drake mallard decoy as the imprinting stimulus. Both the live model and the decoy were silent and moved around the apparatus at a speed of $1.5 \mathrm{~m} . / \mathrm{sec}$. Strength of $1 \mathrm{mpr}$ intıng was measured as the amount of feet followed out of a possible $100 \mathrm{ft}$.

\section{RESULTS}

The results are shown in Figure 1 and Table 1, in terms of mean feet followed for each time interval for each imprinting model. A nonorthogonal two-way analysis of variance was performed using the method of Finn (1972). The model effect was overwhelmingly significant $[F(1,56)=100.36$, $\mathrm{p}<.0001$ ], indicating that the young quail followed the live model more than the decoy. Both the age effect and the Age by Model interaction effect were also significant [for age, $F(6,56)=7.632$, $p<.0001 ;$ for interaction, $F(6,56)=3.388$, $p<.0064]$. The significance of the interaction indicates that these results are applicable only to the

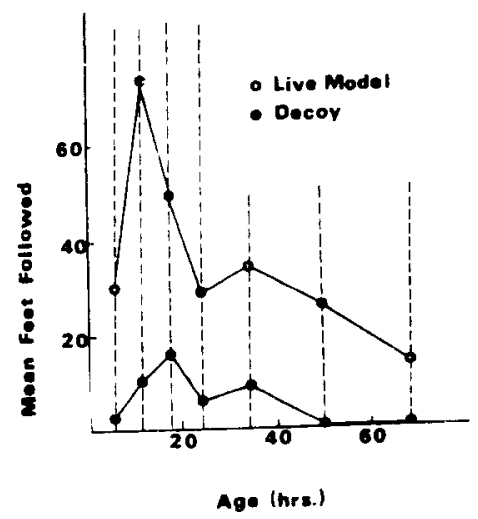

Figure 1. The mean number of feet followed, out of a possible $100 \mathrm{ft}$, expressed as a function of age. 
Table 1 Means and Standard Errors for Live Model and Decoy

\begin{tabular}{clrrc}
$\begin{array}{c}\text { Interval } \\
\text { (hours) }\end{array}$ & Model & $\begin{array}{c}\text { Mean } \\
\text { (feet) }\end{array}$ & N & SE \\
\hline $5-9$ & Live & 31 & 5 & 8.124 \\
$5-9$ & Decoy & 1 & 5 & 1.000 \\
$10-14$ & Live & 74 & 5 & 9.274 \\
$10-14$ & Decoy & 9 & 5 & 3.674 \\
$15-19$ & Live & 49 & 5 & 2.449 \\
$15-19$ & Decoy & 15 & 5 & 5.477 \\
$20-29$ & Live & 30 & 5 & 7.583 \\
$20-29$ & Decoy & 4 & 5 & 2.449 \\
$30-39$ & Live & 38 & 5 & 11.467 \\
$30-39$ & Decoy & 9 & 4 & 5.907 \\
$40-59$ & Live & 27 & 5 & 7176 \\
$40-59$ & Decoy & 0 & 6 & 0.000 \\
$60-79$ & Live & 14 & 5 & 6.595 \\
$60-79$ & Decoy & 0 & 5 & 0.000 \\
\hline
\end{tabular}

age intervals specifically considered in the study. (The error variance for the analysis was 183.37.)

A close inspection of Figure 1 reveals that the live model not only elicited more following, but elicited it earlier and maintained it longer. Even the youngest birds for the live model followed quite well, despite some locomotor difficulty. Maximum following was attained for the live model at the 10-14-h age interval, while for the decoy it was attained at the 15-19-h age interval. Moreover, for the live model, substantial following was attained as late as the 40-59-h age interval, while for the decoy there was no following in this interval.

\section{DISCUSSION}

Previous studies (as presented in the introduction) have indicated that stimuli vary in their ability to elicit imprinting. The present study has demonstrated that much higher following scores can be obtained by using a biologically appropriate, live imprinting stimulus rather than a duck decoy. This study was not designed to specify and tease out the features of the stimuli that are responsible for the increased following. Nevertheless, our data modifies the thesis which argues that imprinting stimuli are nonspecific and bear no relation to the natural parent.

Shapiro and Agnew (1975) and Shapiro (Note 1) have advocated wider use of live models in studies of imprinting. There is little room to doubt that many laboratory studies of imprinting would profit through the adoption of more biologically appropriate imprinting models. Moreover, it should be noted that studies of sexual imprinting (Schein, Fitch, \& Hart, 1962; Schutz, 1965) and innate preferences (Gray, 1964; Kilham, Klopfer, \& Oelke, 1968) have long employed live models with success. On the other hand, while the use of live models is desirable on theoretical grounds, it has its experimental shortcomings. Time and effort are required for the conditioning procedure, and the number of subjects that can be run at any one time may be restricted by the satiation of the live model. The shortcomings, however, remain in the realm of mere inconveniences. The crux of this paper is that they can be overcome and that the resulting imprinting model is both natural and effective in eliciting following in young quail.

In conclusion, it needs to be restated that evaluation of imprinting stimulus parameters is one of the prerequisites for the common understanding of various aspects of the imprinting process. The results of this study offer support for the thesis that availability of a biologically appropriate stimulus is important in inducing responses characteristic of the actual imprinting process. The method presented in this paper should allow researchers in the future to better replicate in their laboratories, imprinting phenomena which occur in nature.

\section{REFERENCE NOTES}

1. Shapiro. L. J. The development of preferences for live temale models of the same spectes or for other species in the White Peking duckling. Paper presented at the meetıng of the American Institute of Biological Sciences. Bloomington. Indiana, August 1970.

2. Storey, A. E.. \& Shapiro, L. J. Preferences of White Peking ducklings for live or inanmate models. Paper presented at the otth annual meetung of the Southern Soctety for Philosophy and Pirchologs. St Louss. Mossouri. 1972.

\section{REFERENCES}

FABricius. E. Zur Ethologie junger Anatiden. Acta Zoologica Fennica, 1951, 68, 1-175.

FinN. J. MULTIVARIANCE. Ann Arbor: National Educational Resources, 1972.

Goodwin. E. B., \& Hess, E. H. Innate visual form preferences in the imprinting behavior of hatchling chicks. Behaviour, 1969, 34, 238-254.

GotTlies. G. Development of spectes identification in birds. Chicago. University of Chicago Press, 1971.

Gray, P. H. The releasers of imprinting: Differential reactions to color as a function of maturation. Journal of Comparative and Physiological Psychology, 1961, 54, 597-601.

Gray, P. H. Interactions of temporal and releasing factors in tamilial recognition of own and ancestral species. Perceptual and Motor Skills, 1964, 18, 445-448.

HEss. E. H. The relatıonship between imprinting and motivation. In Nebraska Sympostum on Motivation. Lincoln: University of Nebraska Press. 1959. Pp. 47-77.

HESS. E. H. \& HESS, D. B. Innate factors in imprinting. Psychonomic Science. 1969. 14. 129-130.

Hoffman, H. S.. \& Ratner, A. M. A reinforcement model of imprinting: Implications for socialization in monkeys and men. Psychological Review. 1973. 80. 527-544.

HuBER. R. J. Imprinting: A test of innate species preference. Perceptual and Motor Skills, 1967, 25, 385-389.

JAYNES. J. Imprinting: The interaction of learned and innate behavior: IV. Generalization and emergent discrimination. Journal of Comparative and Physiological Psychology. 1958. 51. $238-242$. 
Kilham, P.. Klopfer. P. H., \& Oelke. H. Species identification and coloui preterences in chicks. Anımal Behaviour, 1968, 16. 238-244.

Kiopfer, P H. Imprinting: Determining 1ts perceptual basis in ducklings. Journal of Comparative and Physiological Psichology. 1971, 75, 378-385.

Klopfer. P. H. \& Gottlieb, G. Imprinting and behalloral polımorphism: Auditory and visual imprinting in domestic ducks (Anas platyrhnchos) and the involvement of the critical period. Journal of Comparatue and Physiologtcal Psychology. 1962. 55. $126-130$.

Kovach. J. K. Effectiveness of different colors in the elicitation and development of approach behavior in chicks. Behaviour. 1971, 38. 154-168.

LoRENZ, K. Companions as factors in the birds environment 1935. In: Studies in animal and human behavior (Vol. 1). Cambruge Harvard Unversity Press, 1971.

Moltz, H. Rosenblum. L.. \& Stettner, L. J. Some parameters of imprinting etfectueness. Journal of Comparative and Physologlial Psychology, 1960, 53, 297-301.

DzMON. K. L Imprinting and following in Japanese quail (Cotumix coturnix japonica). Quail Quarterly, 1970, 7, 2-12.

Ozmon. K. L Eftect of ECS on imprintıng in Japanese quail (Coturnix coturnix japonica), Journal of Comparative and Physiological Psychology, 1973, 82, 360-367.

RAJECKI. D W. Imprinting in precocial birds: Interpretation. endence. and evaluation. Psychological Bulletm, 1973, 79. 48.58

Ramsay. A. O .d Hess. E. H. A laboratory approach to the study of imprinting Wilson Bulletin. 1954, 66, 196-206.
Schaffer. H. H., \& Hrs, E. H. Color pretercnces in imprinting ublects Zeatschrif tur /erpsychologet. 1959, 16, 161-172

Srhfin. M W. Firch. R J., d Hart. F. M. Sexual stimulus pieterences of eross-species imprinted chickens and turkeys. American Zowlogl:t. 1962. 2. (Abstract)

So hl lman, A H. Hale, E. B., \& Graves, H. B Visual stimulus characteristics for initial approach response in chicks (Gallus domestlcus) Antmal Behaviour. 1970. 18, 461-466.

SCHLTZ. F. Sexuelle Pragung bet Anatiden. Zeitschnft fir Tuerpsichologte. 1965, 22. 50-103.

Shapiro, L. J.. d Agnew. R. L. The development of preferences for lise models in White Peking ducklings. Bulletin of the Psichonomic Soctetl. 1475, 5, 140-142.

Sмiтн, F V Perceptual aspects of imprinting. Symposium of the Zoological Socutti, London, 1962, 8.171-192.

Smith, F. V.. \& BıRD, M. W. The sustained approach of the domestic chick to coloured stimuli. Anımal Behaviour, 1964. 12. $00-63$.

Waller, P. F , d Waller. M. Some relationships between early expertence and later sockal behavior in ducklings. Behavour, 1963. 20. 343-363.

WEIDMANN. U Some experiments on the following and the flocking reaction of mallard ducklings. British Joumal of Anumal Behavor, 1956. 4. 78-79.

(Recenved for publication August 21, 1975; revision accepted November 18,1975 .) 